\title{
Outline
}

This document contains a number of plots to demonstrate the properties of the miQC quality score when compared with a simpler approach. This was run in a directory that contains the mito-filtering repository.

1. Bivariate plot of quality measures with marginal density histograms.

2. Bivariate plot of quality measures, with colour representing miQC quality score.

3. Bivariate plot of quality measures, with colour representing quality score from a 1-dimensional mixture model.

4. Bivariate plot of quality measures, with colour representing which cells are rejected by miQC at the given probability threshold.

5. Bivariate plot of quality measures, with colour representing which cells are rejected by a 1-dimensional mixture model at the given probability threshold.

6. Bivariate plot of quality measures, with colour representing which cells are rejected (or not) by both of the methods (miQC and 1-dimensional mixture model).

7. Bivariate plot of proportion of mitochondrial reads against the total library size, with colour representing miQC quality score. This figure demonstrates that the behaviour of miQC is similar whether considering cellular complexity or library size as a secondary quality measure.

8. Bivariate plot of quality measures, with colour representing which cells are rejected by miQC at a more stringent probability threshold that may induce surprising behaviour.

\section{Richard data}

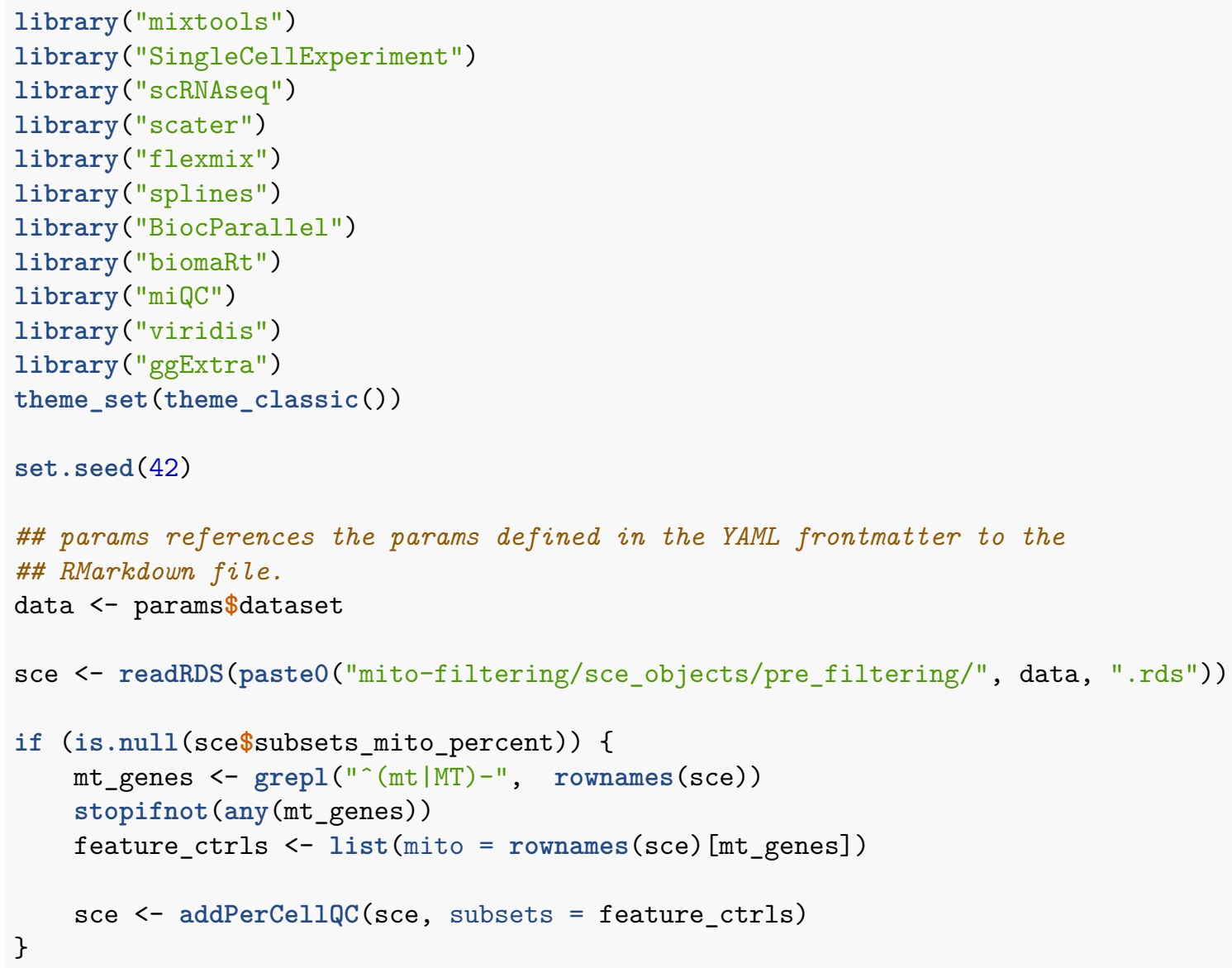




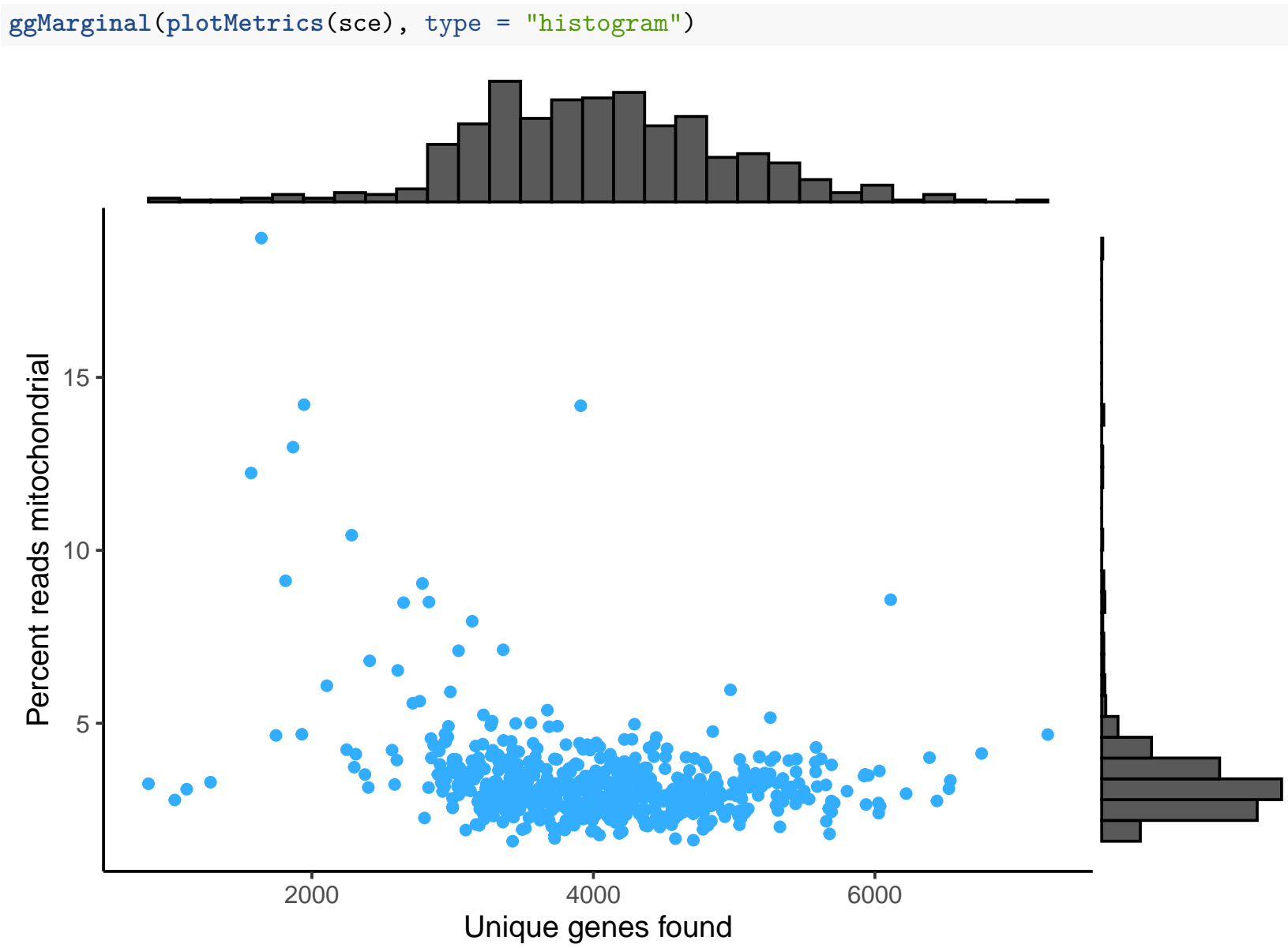

Figure 1: QC metrics with marginal distributions

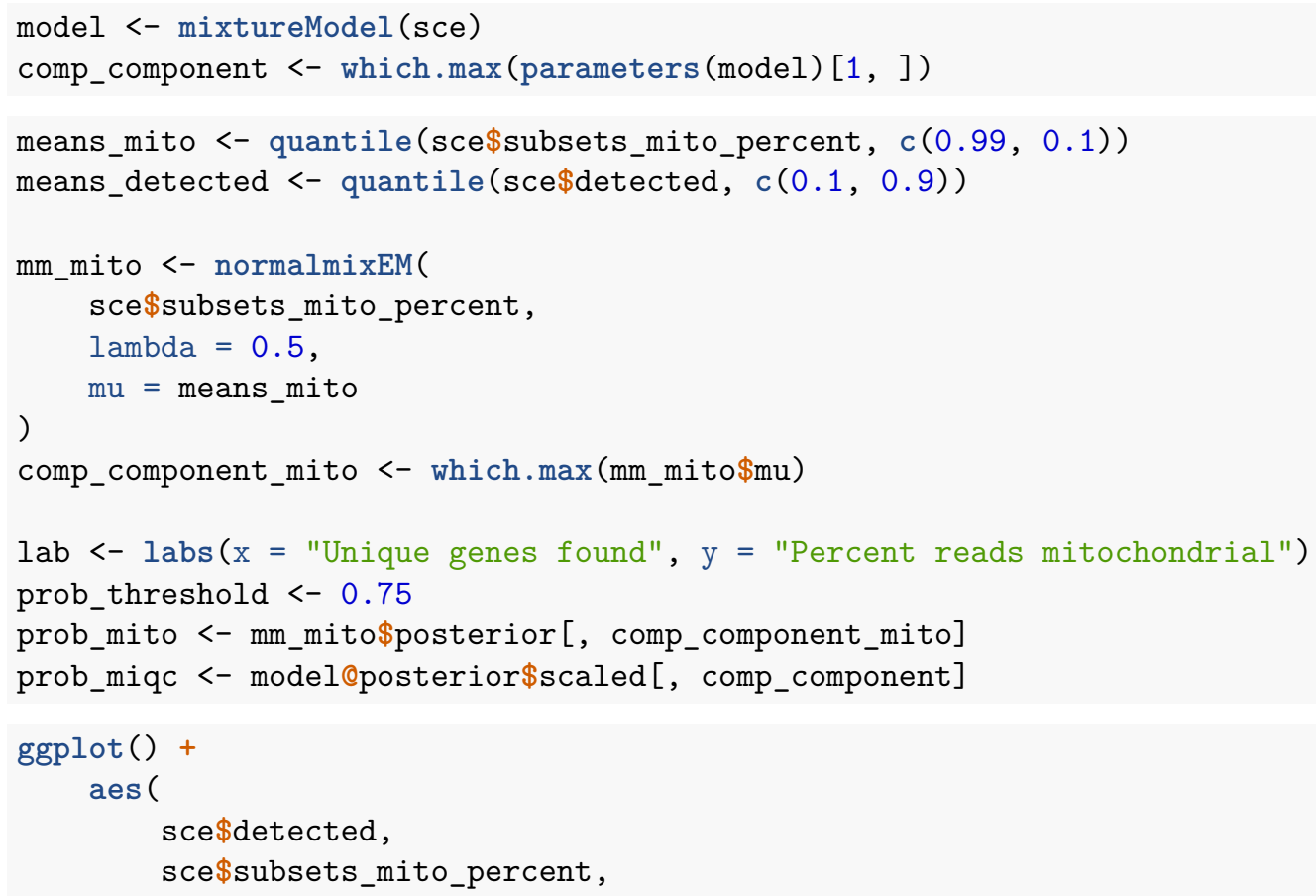


) +

colour $=$ prob_miqc

geom_point() +

$1 \mathrm{ab}+$

scale_colour_viridis(name = "Probability \ncompromised")

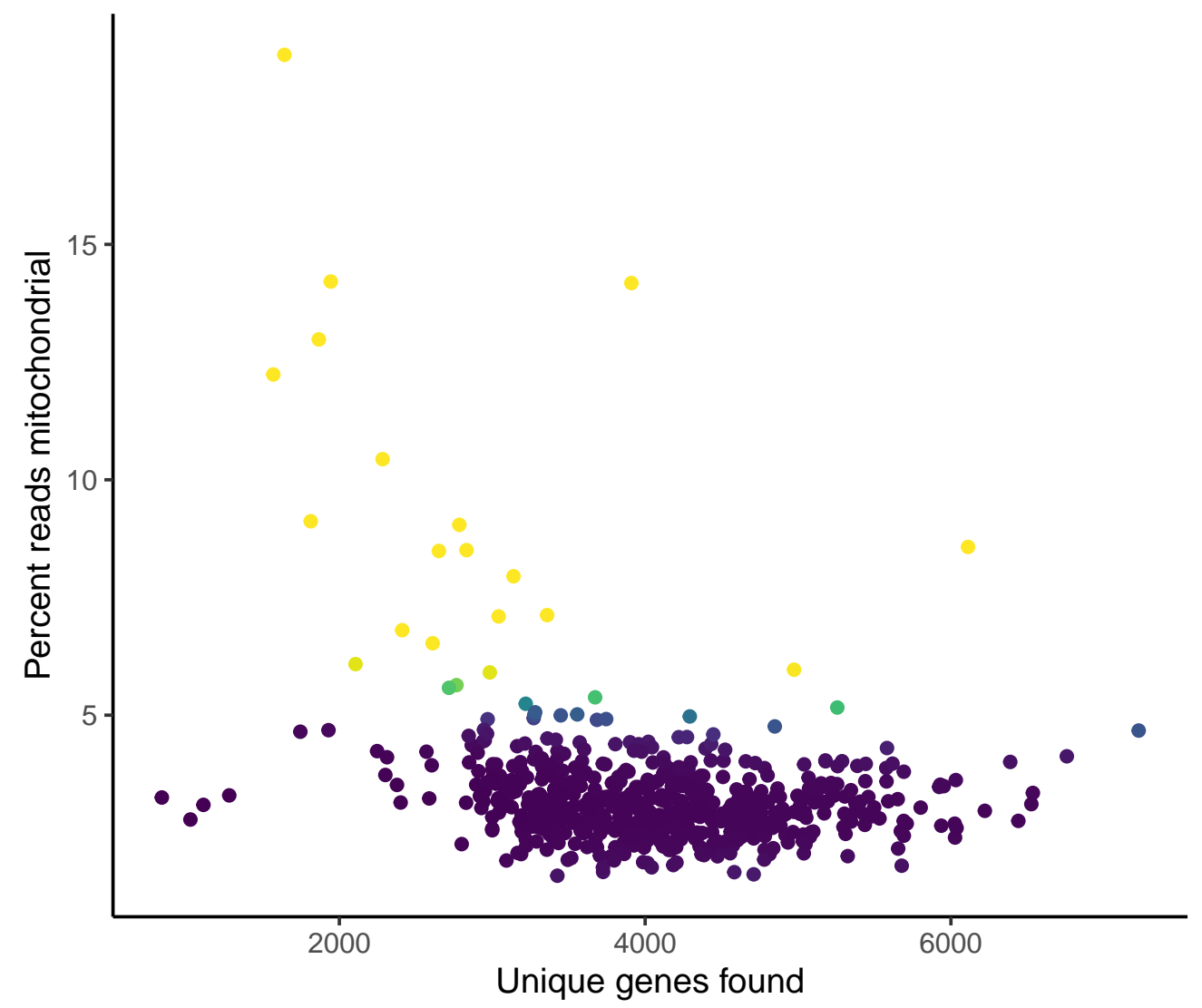

Probability compromised 1.00

0.75

0.50

0.25

Figure 2: Probability compromised, miQC

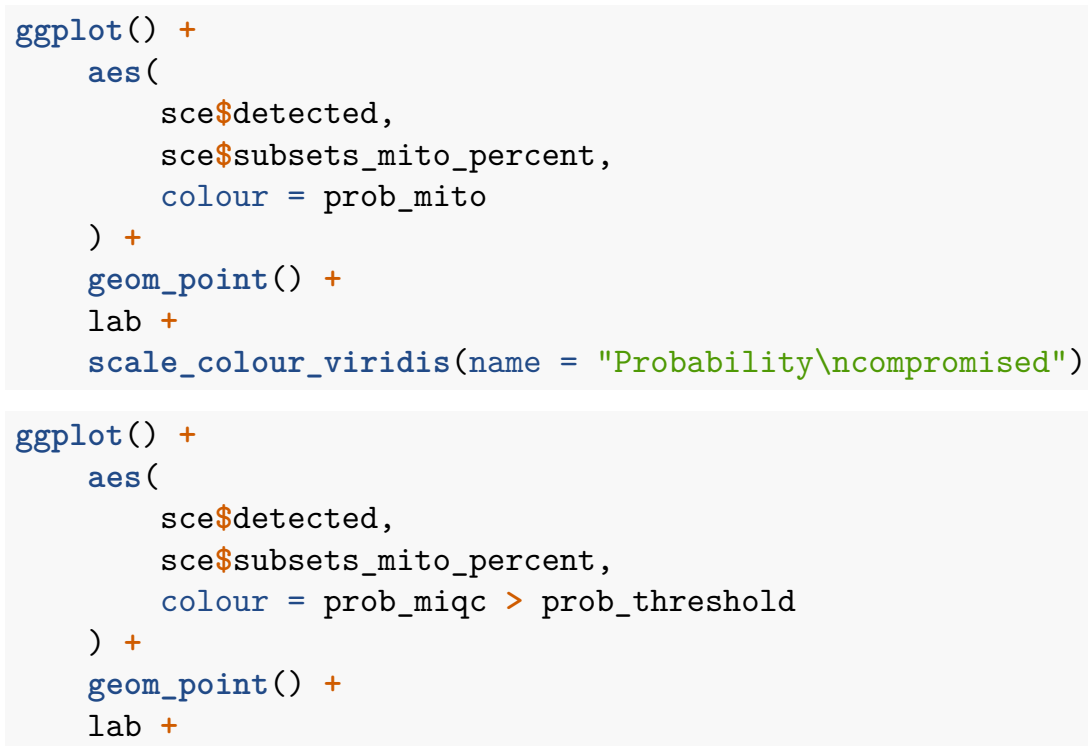




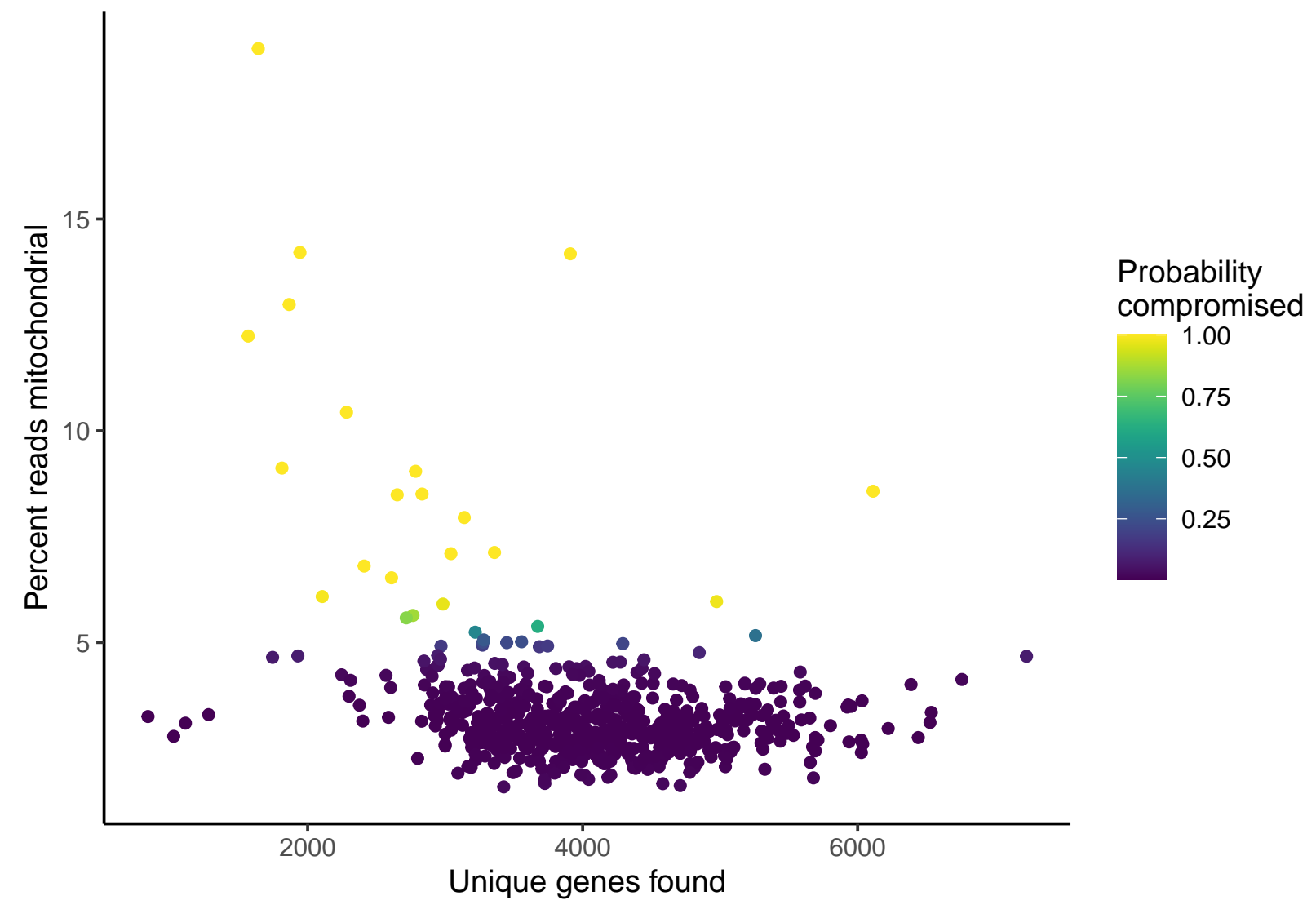

Figure 3: Prob compromised from normal mixture model using percent mito only 

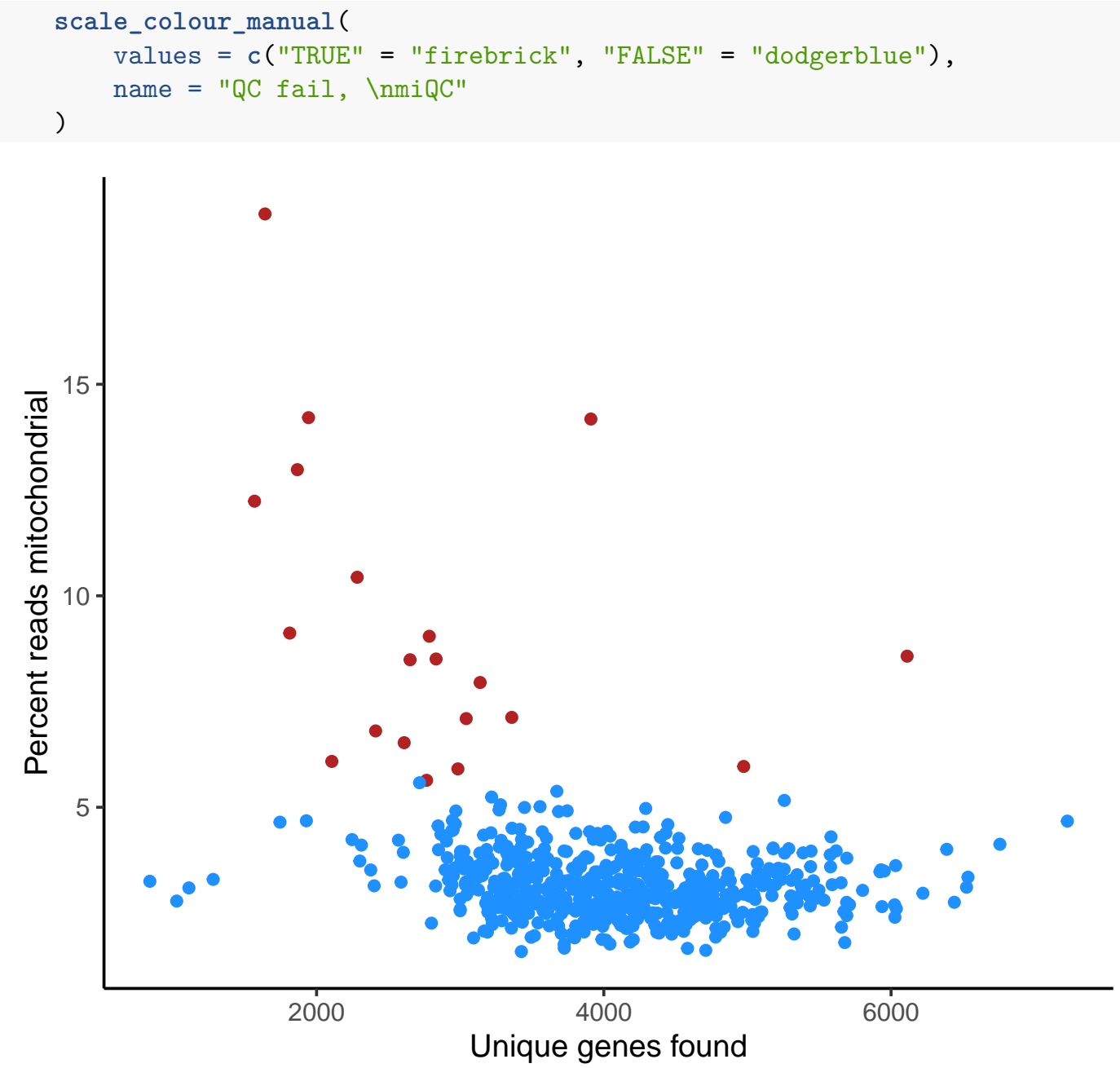

QC fail, miQC

- FALSE

- TRUE

Figure 4: QC pass/fail with miQC

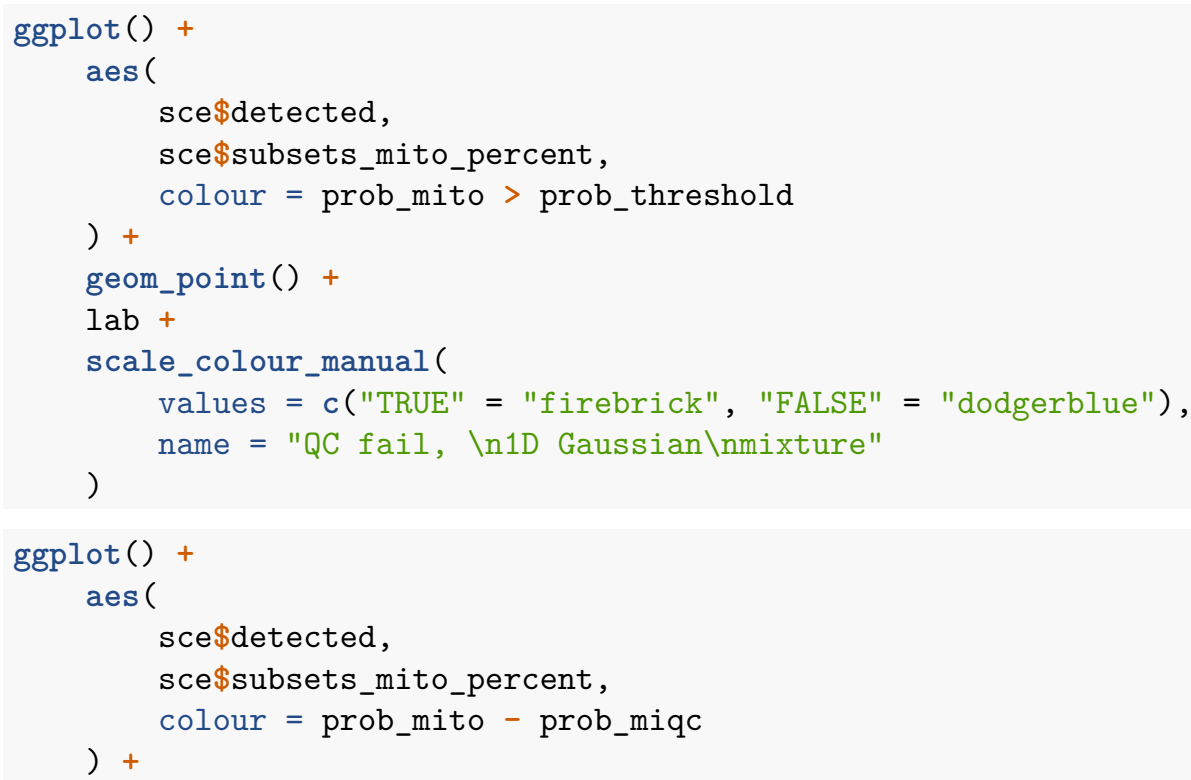




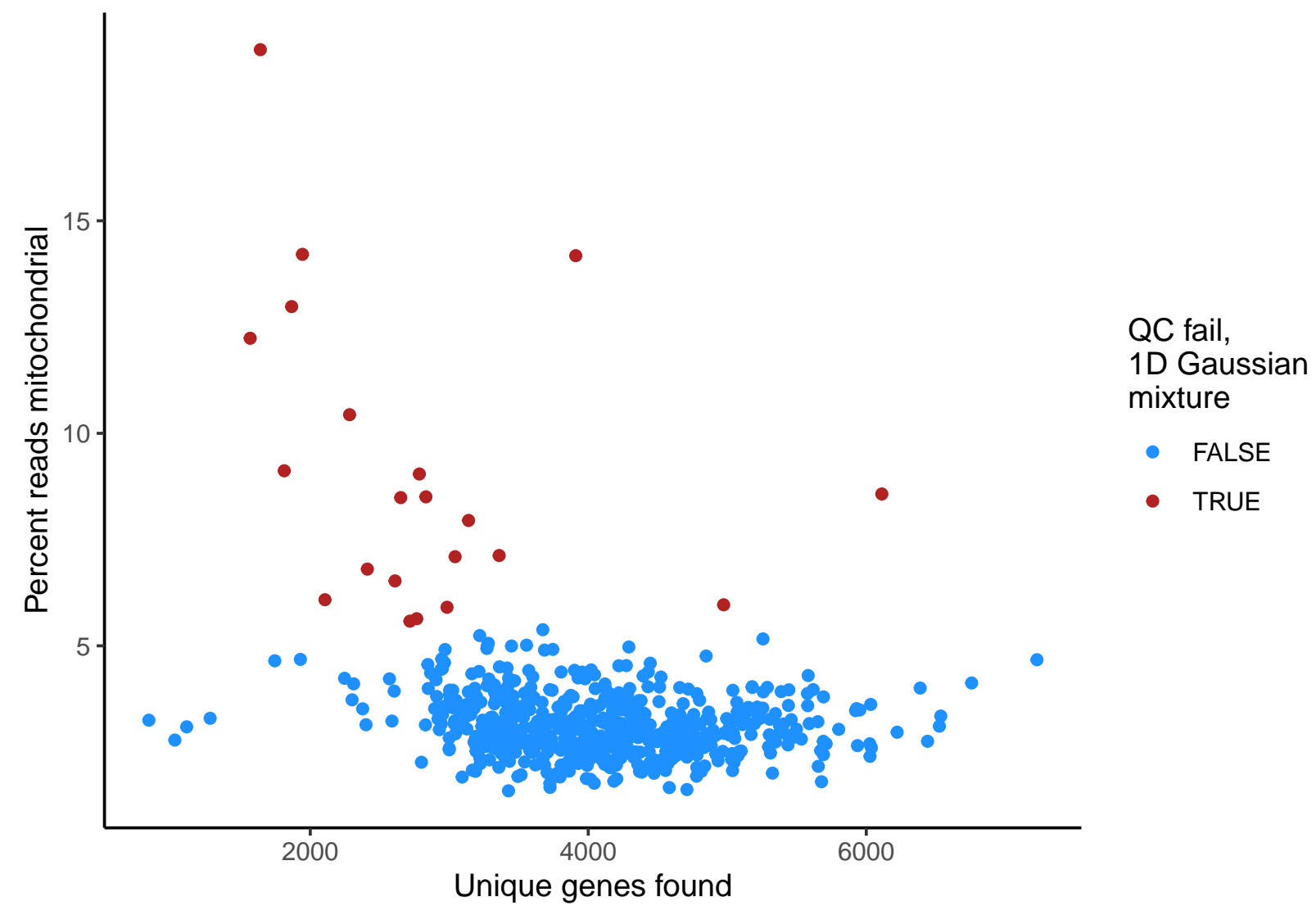

Figure 5: QC pass/fail with 1D mixture model 

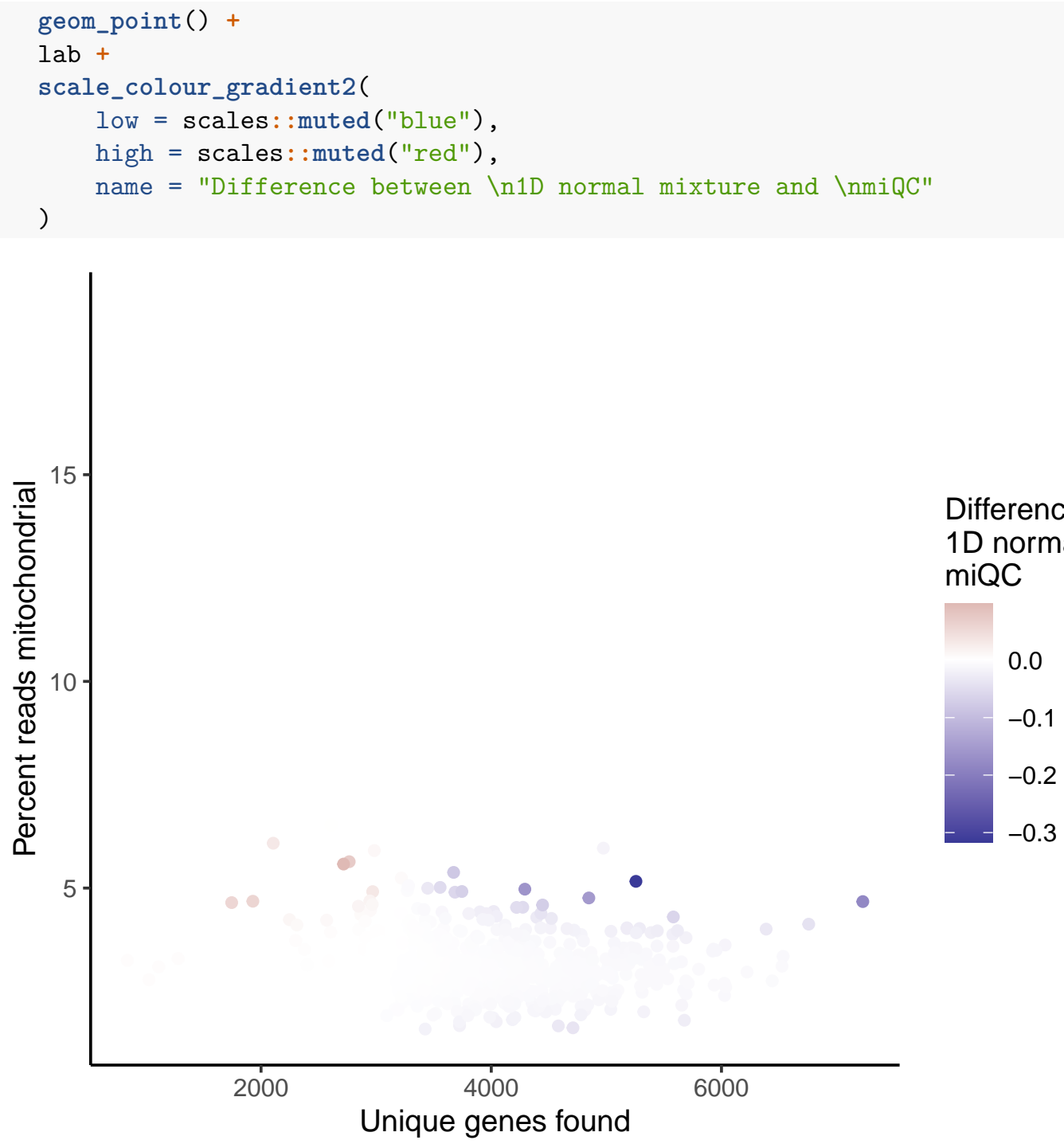

Figure 6: Comparison of posterior probs, 1D mixture and miQC

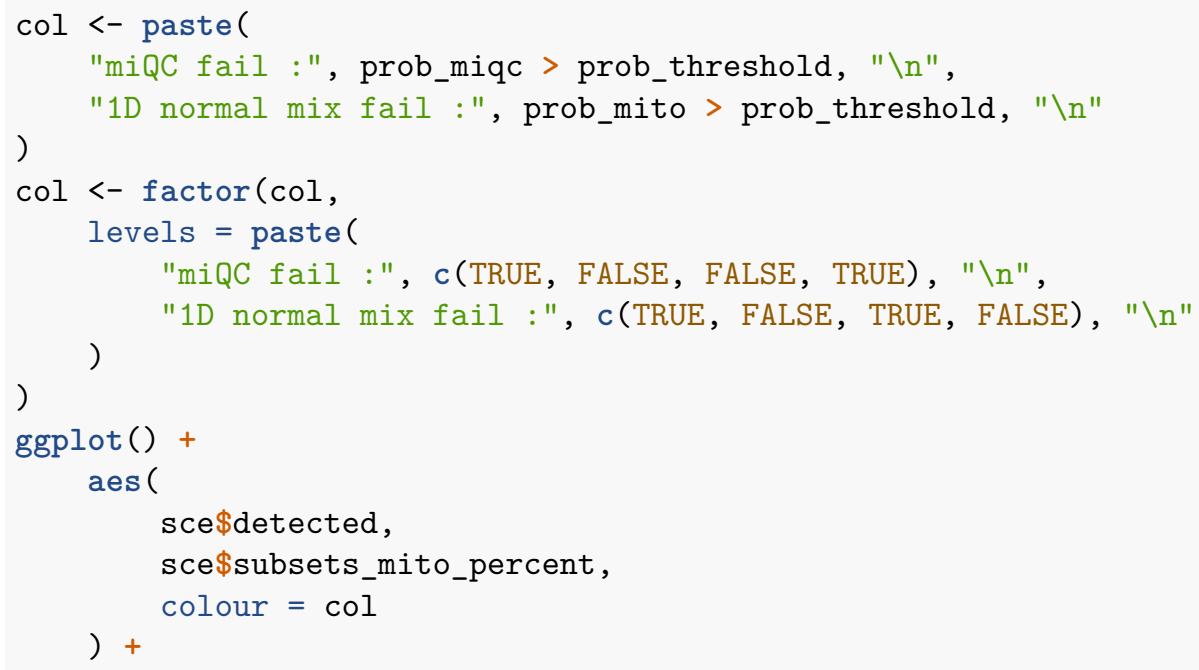



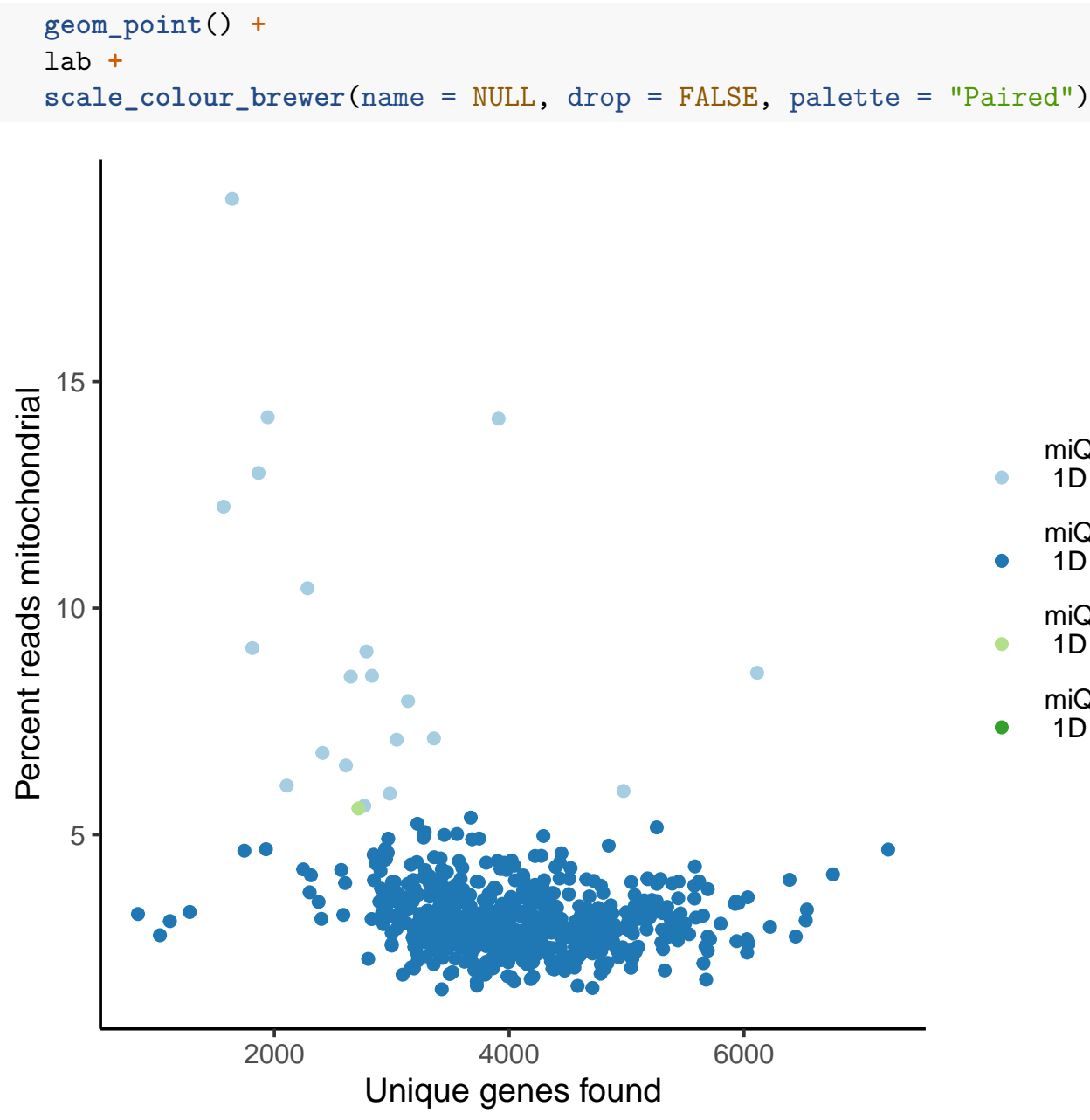

miQC fail : TRUE

- 1D normal mix fail : TRUE

miQC fail : FALSE

- 1D normal mix fail : FALSE

miQC fail : FALSE

- 1D normal mix fail : TRUE

miQC fail : TRUE

- 1D normal mix fail : FALSE

Figure 7: Comparison of pass/fail, 1D mixture and miQC

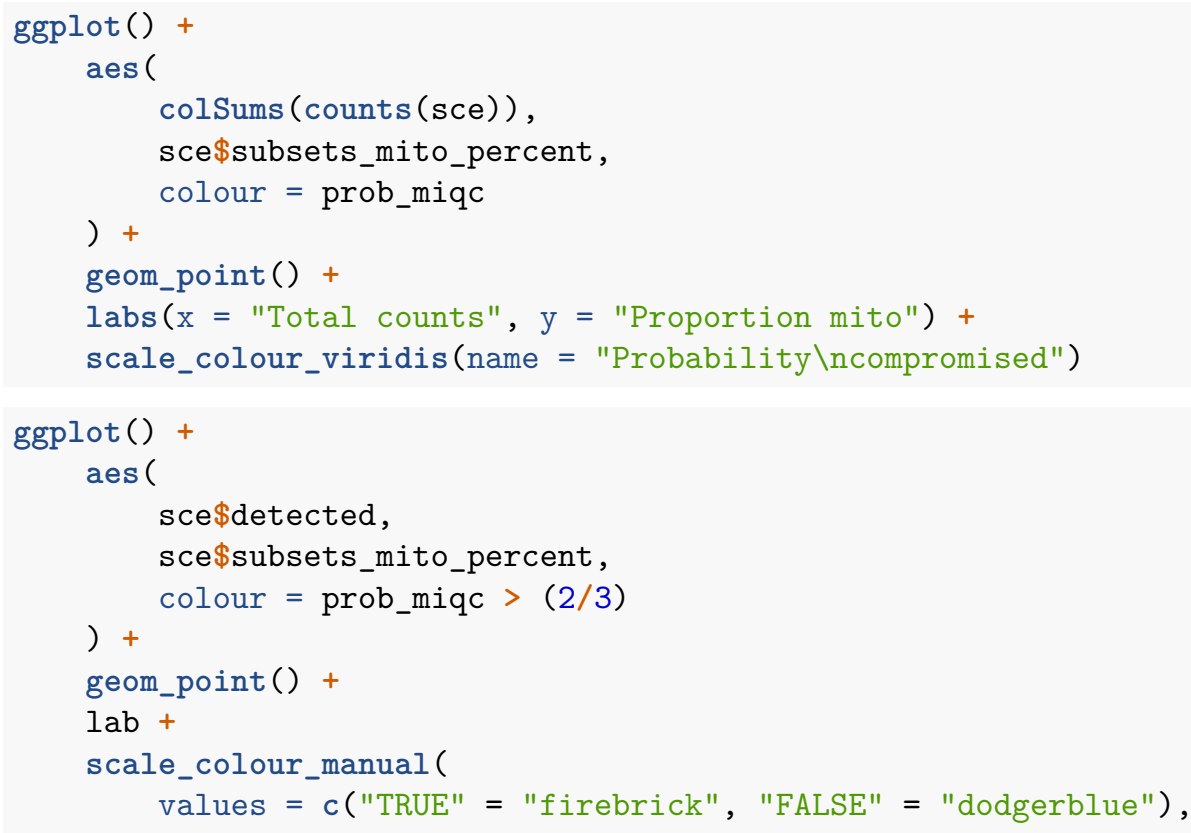




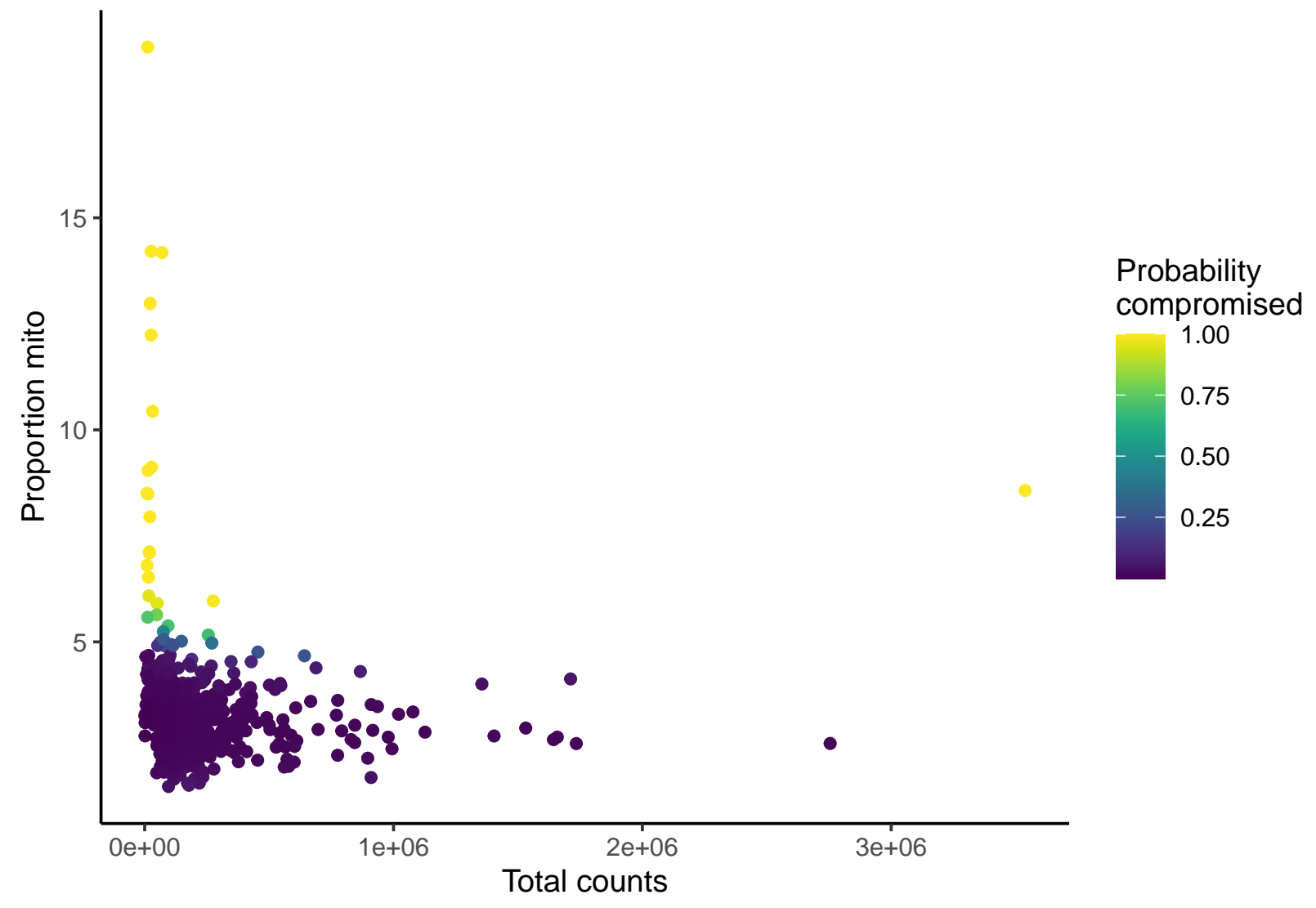

Figure 8: Prob compromised from miQC showing library size (total count). 


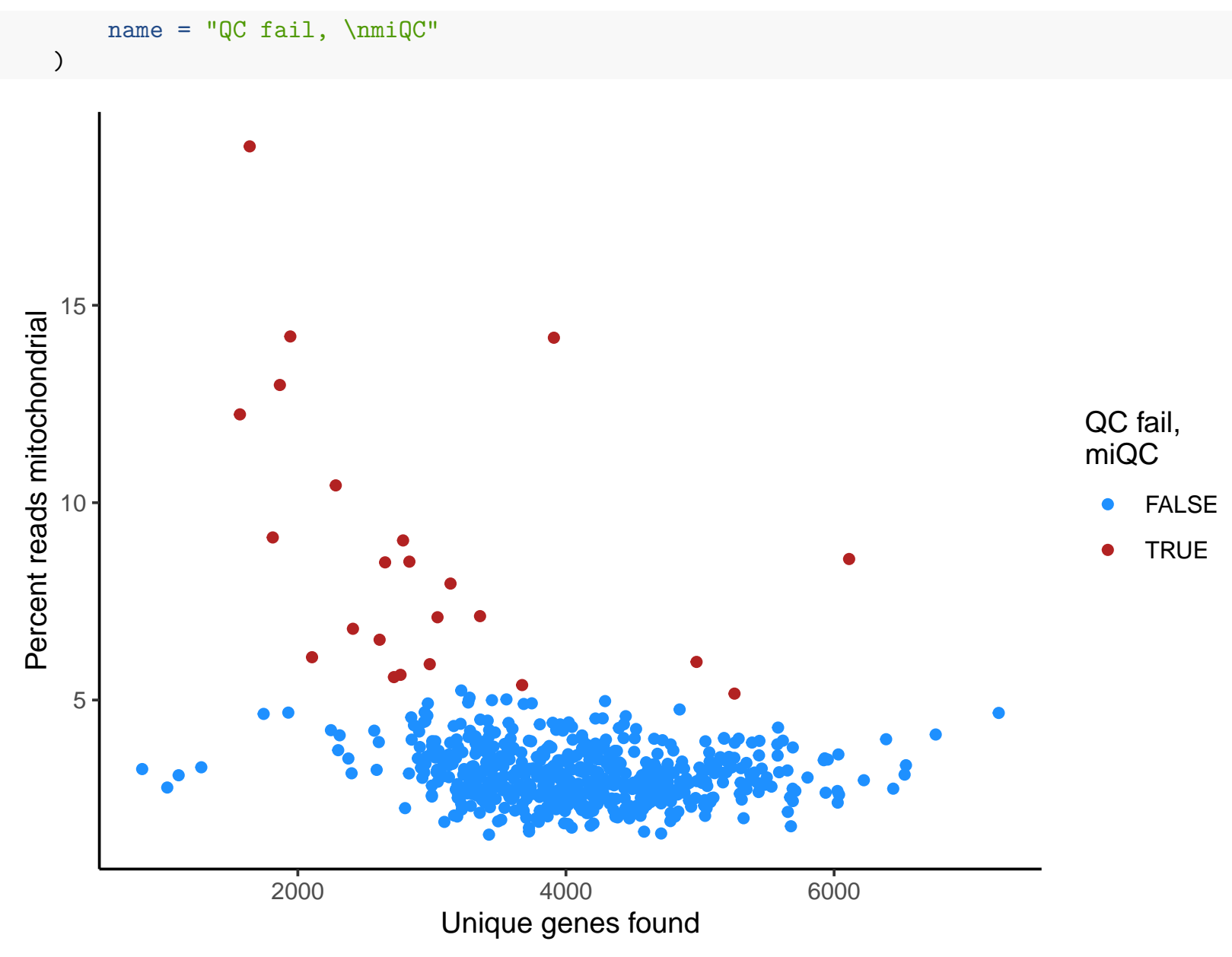

Figure 9: Cells rejected by miQC with a stringent posterior probability threshold of $2 / 3$. This conceptually amounts to the evidence of cells being compromised as double the evidence of cells being non-compromised. 